\title{
Cause and Consequences of Sympathetic Hyperactivity in Chronic Kidney Disease
}

\author{
Peter Kotanko \\ Renal Research Institute, New York, N.Y., USA
}

\section{Key Words}

Chronic kidney disease - Sympathetic nervous system • Muscle sympathetic nerve activity $\cdot$ Moxonidine $\cdot$

Rilmenidine

\begin{abstract}
Patients with chronic kidney disease and patients undergoing hemodialysis treatment show a sustained overactivity of the sympathetic nervous system, which originates from signals arising in the failing kidneys and traveling via afferent renal nerves to cardiovascular centers in the brainstem. Additional important factors are increased levels of angiotensin II and asymmetrical dimethylarginine. The sympathetic overactivity contributes to hypertension and cardiovascular morbidity and mortality in that patient population. Sympathetic overactivity can be reduced by adrenergic receptor blockers, centrally acting sympathicolytic drugs such as moxonidine and rilmenidine, angiotensin-converting enzyme inhibition, and angiotensin II type 1 receptor antagonists. Daily short hemodialysis and long nocturnal hemodialysis may reduce the elevated sympathetic activity, possibly because of an increased clearance of asymmetrical dimethylarginine, an endogenous nitric oxide synthase inhibitor. Prospective trials examining the potential im-
\end{abstract}

pact of both $\beta$-blockers and centrally acting sympatholytic drugs on cardiovascular mortality in chronic kidney disease and hemodialysis patients are very much needed.

Copyright (C) 2006 S. Karger AG, Basel

\section{Background}

Diseases of the cardiovascular system contribute significantly to the morbidity and mortality in patients with chronic kidney disease (CKD) and on hemodialysis treatment.

Hypertension and atherosclerosis are the basis of cardiovascular disease in the majority of dialysis patients. The etiology of high blood pressure in CKD patients is multifactorial. Hypervolemia and activation of the renin angiotensin system are well-recognized important determinants of high blood pressure. It has been recognized over the last 30 years that CKD represents a state of overactivity of the sympathetic nervous system (SNS) and that hypertension in patients with end-stage renal disease (ESRD) may be maintained by an inappropriately high level of sympathetic activation. The issue of sympathetic overactivity in CKD has been the topic of recent excellent reviews $[1,2]$.

\section{KARGER}

Fax +4161306 1234

E-Mail karger@karger.ch

www.karger.com
(C) 2006 S. Karger AG, Basel

0253-5068/06/0241-0095\$23.50/0

Accessible online at:

www.karger.com/bpu 


\section{Physiology of the SNS}

The autonomic nervous system occupies a central position in the normal regulation of the cardiovascular system. This is principally achieved through the effects of the SNS on the function of the heart, large arteries, arterioles, veins, and the kidneys. The parasympathetic nervous system, through vagus nerve regulation of the heart rate, plays a subsidiary role. The role played by circulating catecholamines secreted by the adrenal medulla in cardiovascular regulation in general, and blood pressure control in particular, is a contentious issue.

Norepinephrine (NE) is the main neurotransmitter of the SNS. NE binds to postsynaptic $\alpha$ - and $\beta$-adrenergic receptors. Among other actions, $\alpha$-adrenergic receptors mediate vasoconstriction and $\beta$-adrenergic receptors mediate increases in heart rate, inotropy, and peripheral vasodilatation. A feedback loop involves presynaptic adrenergic receptors. Genetic variants of both $\alpha_{2^{-}}$and $\beta_{2^{-}}$ adrenergic receptors have been linked to essential hypertension $[3,4]$.

The influences of the SNS on normal cardiovascular control are both short- and long-term. Examples of the short-term sympathetic nervous circulatory control are the neural modification of venous capacitance, arteriolar resistance, and heart rate with upright posture and the regulation of regional blood flow. In healthy subjects, long-term circulatory control involves in particular the regulation of salt and water balance through effects of the SNS on renin secretion and renal tubular reabsorption of sodium.

Schemes of the organization of circulatory control rightly emphasize the preeminence of reflex blood pressure homeostasis. On the afferent side, this is achieved through arterial and low-pressure receptors, with reflex outputs to the heart, resistance vessels, capacitance vessels, and the kidneys. Afferent and efferent signals integrate the kidneys into sympathetic control. The central nervous system integration of high-pressure baroreceptor influences particularly involves the nucleus tracus solitarius of the brainstem. Efferent sympathetic activity in humans accurately and appropriately adjusts with change in arterial pressure. There exists a precise relationship between sympathetic nervous response and the magnitude of pressure change. A fall in arterial blood pressure results in an activation of the SNS with a consecutive rise of heart rate and heart inotropy, as well as constriction of resistance and of capacitance vessels. In summary, these responses result in a rise of blood pressure.

\section{Clinical Assessment of the SNS}

The activity of the SNS can be studied mainly by three techniques: (1) biochemical methods (static measurements of plasma NE concentration; measurements of NE spillover rates), (2) microneurography in sympathetic muscle nerve fibers, and (3) power spectral analysis of heart rate and blood pressure variability.

\section{Biochemical Methods}

Static measurement of plasma NE concentration provides a useful global guide to SNS function, although limitations have to be kept in mind. One technical weakness is the dependence of the plasma concentration on the rate at which the transmitter is removed from plasma, after its overflow to the circulation, and not only on sympathetic nerve firing and NE release. Since plasma NE is a global index of SNS activity, it does not provide information on regional patterns of sympathetic activation. NE release can be studied using sophisticated radiotracer-derived measurements of the appearance rates of $\mathrm{NE}$ in plasma, from individual organs or from the body as a whole. This method provides useful insights into regional sympathetic innervation [5]. Its major shortcoming is the complicated technical setup which requires infusion of radiolabeled tracers.

\section{Microneurography}

Microneurography was first developed in the 1970s [6] and is a method for intraneural recording of sympathetic activity in conscious humans. The method requires the percutaneous insertion of tungsten microelectrodes into a peripheral nerve (generally, the peroneal or radial nerves are used) to record multiunit spontaneous postganglionic sympathetic action potentials. Thus, this techniques allows the measurement of sympathetic nerve traffic targeted to the skeletal muscle circulation (muscle sympathetic nerve activity; MSNA). The method is remarkably safe and well tolerated but it requires advanced technical expertise, and therefore, the availability of MSNA measurements is limited.

\section{Power Spectral Analysis}

Power spectral analysis is a computer-based technique that quantifies the variability in hemodynamic parameters in the frequency domain. Power spectral analyses of the heart rate variability indicate that fluctuations in heart rate are not random, but exhibit periodicities of a fairly constant frequency. The first component is synchronous with respiration and occurs at relatively high fre- 
quency ( $\mathrm{HF}$ band $0.15-0.4 \mathrm{~Hz}$ ). A second component is identified at lower frequency (LF band $0.04-0.15 \mathrm{~Hz}$ ). The HF variation in the R-R interval mainly reflects vagal activity. The interpretation of the LF component is somewhat controversial, since the LF component is influenced by both parasympathetic and sympathetic activity. By evaluating the relative preponderance of these two components, it is possible to estimate the level of vagal and sympathetic activation in humans at rest or during activity. A rise of the $\mathrm{LF} / \mathrm{HF}$ ratio is consistent with greater sympathetic activation. Recently, procedures to standardize the interpretation of power spectral analysis data have been proposed [7]. The vagal activity may be better reflected in the beat-to-beat variability of diastolic blood pressure. This limits the application of the method since continuous beat-to-beat blood pressure measurements are necessary. Continuous beat-to-beat hemodynamic monitoring including blood pressure can be performed with the Task Force Monitor [8].

\section{Evidence for Increased SNA in CKD and Hemodialysis Patients}

The first indications pointing towards an increased sympathetic nerve activity in CKD came from measurements of elevated plasma catecholamine concentrations in the late 1970s [9]. In 1992, by measurements of MSNA, Converse et al. [10] found that the basal level of sympathetic firing was more than doubled in hypertensive hemodialysis patients compared with age-matched healthy normotensive volunteers with normal renal function. The individual firing rates were remarkably stable throughout the interdialytic period. An increase in MSNA has been found in many types of human hypertension (renovascular hypertension, malignant hypertension, pre-eclampsia, hypertension associated with obesity, and hypercapnia), renal disorders (human polycystic kidney disease, partial renal ablation, and other animal models of renal disease), smoking, obesity, and sleep apnea.

\section{Origin of Increased SNA in CKD}

Signals arising in the failing kidneys seem to mediate sympathetic activation in CKD (fig. 1). Bilateral nephrectomy normalizes the increased SNA in dialysis patients and after renal transplantation [11]. These observations point towards the kidneys as the origin of increased SNA,

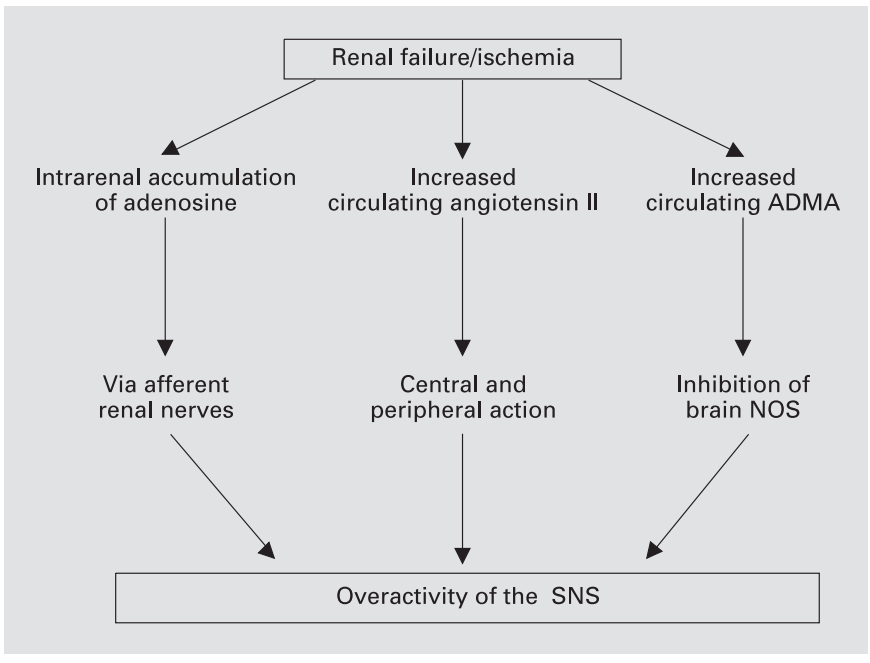

Fig. 1. Sympathetic overactivity in CKD originates from different pathways, including afferent renal nerves, and increased levels of circulating angiotensin II and ADMA. Circulating ADMA may stimulate the SNS by an inhibition of brain nitric oxide synthase (NOS). The consecutive fall in brain nitric oxide may contribute to an increase in central sympathetic outflow.

with renal ischemia being the main factor. Normally, the kidneys are richly innervated not only by sympathetic efferent fibers but also by sensory afferent fibers that signal the central nervous system of chemical and mechanical changes in the kidney and the renal pelvis. The local accumulation of adenosine in oxygen-depleted renal tissue may play a prominent role [12]. These afferent signals travel via renal nerves to the brainstem and increase the central sympathetic outflow. Consistent with this hypothesis is the observation that selective renal deafferentiation ameliorates SNA increase in animal models of renal hypertension.

Angiotensin II can stimulate SNA by a direct effect on the vasomotor center in the brain stem. In addition, angiotensin II increases the NE release at the adrenergic nerve terminal and inhibits the presynaptic reuptake of NE.

It is likely that a decrease in nitric oxide availability contributes to sympathetic hyperactivity [13]. In renal failure, the concentration of circulating ADMA, an endogenous inhibitor of nitric oxide synthase, is increased, and increased levels of ADMA predict adverse events (both death and cardiovascular) among ESRD patients [14]. In this study, a strong positive correlation between ADMA and NE has been observed in multivariate analyses. 
Elevated SNA is not normalized after successful renal transplantation, making circulating uremic toxins as triggers of sympathetic overactivity less likely [11].

Stimulation of carotid chemoreceptors could increase SNA, because dialysis patients tend to be mildly acidemic. Sleep apnea is highly prevalent in the dialysis population. It may sensitize the carotid body chemoreflex, leading to sustained sympathetic overactivity and hypertension.

\section{Consequences of Sympathetic Overactivity}

Cardiovascular disease is highly prevalent among patients with ESRD and is responsible for the increased mortality in that population. Hypertension plays a key role in the development of cardiovascular complications. Traditionally, hypertension in dialysis patients has been viewed as being largely volume dependent. Now, there is mounting evidence that sympathetic hyperactivity significantly contributes to the generation and maintenance of high blood pressure in ESRD patients. In CKD, an increased systemic vascular resistance with an inappropriately normal cardiac output suggests that either impaired vasodilator mechanisms or augmented vasoconstrictor mechanisms play an important role in the pathogenesis of high blood pressure. Besides blood pressure elevation, a tonic increase in sympathetic outflow causes functional and structural alterations at the myocardium, large arteries, and the kidneys. Sympathetic overactivity may promote cardiac arrhythmias, increase myocardial oxygen demand, induce left ventricular hypertrophy, and reduce the compliance of the large arteries. Interesting observations point towards relationships between the autonomous nervous system, inflammatory and procoagulatory pathways. In this context, the vagal and sympathetic system may act synergistically [15].

The deleterious effects of sympathetic overactivity have been convincingly demonstrated in a landmark study by Zoccali et al. [16] in a cohort of 228 patients undergoing chronic hemodialysis. In these patients, the plasma concentration of NE was used as a measure of sympathetic activity. In a multivariate Cox regression model that included all univariate predictors of death, as well as the use of $\beta$-blockers, plasma NE proved to be an independent predictor of fatal and nonfatal cardiovascular events. The adjusted relative risk for cardiovascular complications in patients with plasma NE concentrations above the 75th percentile of the study population was 1.9 times higher than in those below this threshold.

\section{How to Fight Sympathetic Hyperactivity in CKD?}

Sympathetic hyperactivity can be blocked at several levels: adrenergic receptor blockers bind to either $\alpha$ - and/ or $\beta$-adrenergic receptors. $\alpha$-Blockers, such as prazosin and doxazosin, can be effectively used in patients with CKD. $\alpha$-Blockers may increase the rate of intradialytic hypotension.

$\beta$-Blockers have been shown to reduce mortality in patients with coronary artery disease or congestive heart failure. A prospective observational study did suggest a benefit of $\beta$-blockers in diabetic dialysis patients [17]. Recently, a prospective randomized placebo-controlled trial of carvedilol in 114 dialysis patients with dilated cardiomyopathy demonstrated a significant reduction both in deaths and hospital admissions [18]. $\beta$-Blockers can be safely used in dialysis patients by applying a supervised low-dose regimen [19]. Registry data reveal that only a minority of dialysis patients are on $\beta$-blockers. A prospective trial examining the potential impact of $\beta$-blockers on cardiovascular mortality in hemodialysis patients is very much needed.

Centrally acting sympatholytic drugs have been shown to reduce sympathetic overactivity. The older drugs of that group are clonidine and $\alpha$-methyldopa. Today, the newer selective $I_{1}$ imidazoline receptor agonists (which may also have a central $\alpha_{2}$-receptor agonistic mode of action) moxonidine and rilmenidine are preferred because of less adverse reactions. Moxonidine has been shown at a regular dose of $0.4 \mathrm{mg} /$ day to reduce sympathetic overactivity. Moxonidine is used in daily doses of $0.2-0.6 \mathrm{mg}$ in the treatment of hypertension. Higher doses (1.8$6.0 \mathrm{mg} /$ day) were associated with increased mortality in the MOXCON trial [20]. Moxonidine in addition to the angiotensin II type 1 (AT-1) blocker eprosartan has been shown to normalize elevated MSNA in patients with advanced coronary flow reserve [21]. Rilmenidine may be used in dialysis patients at a dose of $1 \mathrm{mg}$ three times a week. Interestingly, despite its sympathicolytic activity, rilmenidine preserves sympathetic responses during mental stress and tilting, with the latter underlying a freedom from postural hypotension on the drug [22]. This aspect may be of relevance for the sympathicolytic treatment of hemodialysis patients prone to intradialytic hypotension. Low-dose use of moxonidine and rilmenidine [23] in patients with CKD is safe. Both moxonidine and rilmenidine are not available in the USA. No prospective data on the impact of centrally acting sympathicolytic agents in patients with renal insufficiency are available. Since 
there is a strong rationale for the use of these drugs in CKD, prospective trials should be undertaken.

Angiotensin-converting enzyme inhibition and AT-1 blockade interfere with the central sympathetic actions of angiotensin II and lower sympathetic overactivity in CKD patients. Both the angiotensin-converting enzyme inhibitor enalapril [24] and the AT-1 receptor blocker losartan [25] reduce sympathetic overactivity, but neither drug normalizes MSNA completely. Preliminary data have shown that daily short dialysis or nocturnal long dialysis reduce MSNA when compared with thrice weekly conventional hemodialysis [26], possibly due to a lowering of ADMA levels. Hemodiafiltration may be more effective than conventional hemodialysis in removing ADMA [27], but prospective data are needed. Treatment of sleep apnea is an additional means to reduce sympathetic overactivity.

\section{References}

$\checkmark 1$ Koomans HA, Blankestijn PJ, Joles JA: Sym- 10 Converse RL Jr, Jacobsen TN, Toto RD, et al: pathetic hyperactivity in chronic renal failure: a wake-up call. J Am Soc Nephrol 2004;15: 524-537.

2 Blankestijn PJ: Sympathetic hyperactivity in $>1$ chronic kidney disease. Nephrol Dial Transplant 2004; 19:1354-1357.

-3 Svetkey LP, Timmons PZ, Emovon O, Anderson NB, Preis L, Chen YT: Association of hypertension with beta2-and alpha2c10-adrenergic receptor genotype. Hypertension 1996;27: 1210-1215.

$\checkmark 4$ Kotanko P, Binder A, Tasker J, et al: Essential hypertension in African Caribbeans associates with a variant of the beta2-adrenoceptor. Hypertension 1997;30:773-776.

$\checkmark 5$ Esler M, Willett I, Leonard P, et al: Plasma noradrenaline kinetics in humans. J Auton Nerv Syst 1984;11:125-144.

-6 Vallbo AB, Hagbarth KE, Torebjork HE, Wallin BG: Somatosensory, proprioceptive, and sympathetic activity in human peripheral nerves. Physiol Rev 1979;59:919-957.

$>7$ Heart rate variability: standards of measurement, physiological interpretation and clinical use. Task Force of the European Society of Cardiology and the North American Society of Pacing and Electrophysiology. Circulation 1996;93:1043-1065.

-8 Gratze G, Fortin J, Holler A, et al: A software package for non-invasive, real-time beat-tobeat monitoring of stroke volume, blood pressure, total peripheral resistance and for assessment of autonomic function. Comput Biol Med 1998;28:121-142.

9 Brecht HM, Ernst W, Koch KM: Plasma noradrenaline levels in regular haemodialysis patients. Proc Eur Dial Transplant Assoc 1976; 12:281-290.
Sympathetic overactivity in patients with chronic renal failure. N Engl J Med 1992;327: 1912-1918.

11 Hausberg M, Kosch M, Harmelink P, et al: Sympathetic nerve activity in end-stage renal disease. Circulation 2002;106:1974-1979.

12 Katholi RE, Winternitz SR, Oparil S: Decrease in peripheral sympathetic nervous system activity following renal denervation or unclipping in the one-kidney one-clip Goldblatt hypertensive rat. J Clin Invest 1982;69:55-62.

13 Krukoff TL: Central actions of nitric oxide in regulation of autonomic functions. Brain Res Brain Res Rev 1999;30:52-65.

14 Mallamaci F, Tripepi G, Maas R, Malatino L, Boger R, Zoccali C: Analysis of the relationship between norepinephrine and asymmetric dimethyl arginine levels among patients with end-stage renal disease. J Am Soc Nephrol 2004;15:435-441.

15 Tracey KJ: The inflammatory reflex. Nature 2002;420:853-859.

16 Zoccali C, Mallamaci F, Parlongo S, et al: Plasma norepinephrine predicts survival and incident cardiovascular events in patients with end-stage renal disease. Circulation 2002;105: 1354-1359.

17 Koch M, Thomas B, Tschope W, Ritz E: Survival and predictors of death in dialysed diabetic patients. Diabetologia 1993;36:11131117.

18 Cice G, Ferrara L, D’Andrea A, et al: Carvedilol increases two-year survivalin dialysis patients with dilated cardiomyopathy: a prospective, placebo-controlled trial. J Am Coll Cardiol 2003;41:1438-1444.

19 Agarwal R: Supervised atenolol therapy in the management of hemodialysis hypertension. Kidney Int 1999;55:1528-1535.
20 Cohn JN, Pfeffer MA, Rouleau J, et al: Adverse mortality effect of central sympathetic inhibition with sustained-release moxonidine in patients with heart failure (MOXCON). Eur J Heart Fail 2003;5:659-667.

21 Neumann J, Ligtenberg G, Oey L, Koomans HA, Blankestijn PJ: Moxonidine normalizes sympathetic hyperactivity in patients with eprosartan-treated chronic renal failure. J Am Soc Nephrol 2004;15:2902-2907.

22 Esler M, Lux A, Hastings J, Socratous F, Lambert G: Rilmenidine sympatholytic activity preserves mental and orthostatic sympathetic response and epinephrine secretion. J Hypertens 2004;22:A7-A8.

23 Aparicio M, Dratwa M, el Esper N, et al: Pharmacokinetics of rilmenidine in patients with chronic renal insufficiency and in hemodialysis patients. Am J Cardiol 1994;74:43A-50A.

24 Ligtenberg G, Blankestijn PJ, Oey PL, et al: Reduction of sympathetic hyperactivity by enalapril in patients with chronic renal failure. N Engl J Med 1999;340:1321-1328.

25 Klein IH, Ligtenberg G, Oey PL, Koomans HA, Blankestijn PJ: Enalapril and losartan reduce sympathetic hyperactivity in patients with chronic renal failure. J Am Soc Nephrol 2003; 14:425-430.

26 Zilch O, Vos PF, Oey LP, Cramer MM, Koomans HA, Blankestijn PJ: Daily dialysis reduces peripheral vascular resistance and sympathetic activity (abstract). J Am Soc Nephrol 2001; 12.

27 Schroder M, Riedel E, Beck W, Deppisch RM, Pommer W: Increased reduction of dimethylarginines and lowered interdialytic blood pressure by the use of biocompatible membranes. Kidney Int Suppl 2001;78:S19-S24. 